\title{
Positive Youth Development: Developing, Implementing, and Sustaining Music-Based Services for Emerging Adults Experiencing Homelessness
}

\author{
Brian Kelly \\ bkelly6@luc.edu
}

Follow this and additional works at: https://ecommons.luc.edu/socialwork_facpubs

Part of the Social Work Commons

\section{Author Manuscript}

This is a pre-publication author manuscript of the final, published article.

\section{Recommended Citation}

Kelly, Brian. Positive Youth Development: Developing, Implementing, and Sustaining Music-Based Services for Emerging Adults Experiencing Homelessness. Emerging Adulthood, 7, 5: 331-341, 2019. Retrieved from Loyola eCommons, Social Work: School of Social Work Faculty Publications and Other Works, http://dx.doi.org/10.1177/2167696818777347

This Article is brought to you for free and open access by the Faculty Publications and Other Works by Department at Loyola eCommons. It has been accepted for inclusion in Social Work: School of Social Work Faculty Publications and Other Works by an authorized administrator of Loyola eCommons. For more information, please contact ecommons@luc.edu.

\section{c) (i) $\ominus$}

This work is licensed under a Creative Commons Attribution-Noncommercial-No Derivative Works 3.0 License. (c) Sage Journals, 2019. 
Positive Youth Development: Developing, Implementing, and Sustaining Music-Based Services for Emerging Adults Experiencing Homelessness

Brian L. Kelly, PhD

School of Social Work, Loyola University Chicago, Chicago, IL, USA

Acknowledgements: The author would like to thank the young people and staff of Teen Living Programs who participated in the study, Drs. Mark Mattaini, Dina Birman, and Cassandra McKay-Jackson for their feedback and support in conceptualizing and executing the study, and Olga Konyakova for her assistance in developing the manuscript.

Funding: This study was funded through the Fahs-Beck Fund for Research and Experimentation Doctoral Dissertation Grant Program and the University of Illinois at Chicago Chancellor's Graduate Research Fellowship.

Address correspondence to: Brian L. Kelly, Associate Professor, Loyola University Chicago, School of Social Work, 1 East Pearson Street, Chicago, IL 60611. Phone: 312.915.7479. Email: bkelly6@luc.edu

Keywords: homelessness, Positive Youth Development, transitional living programs, programming, music-based services 


\begin{abstract}
Research suggests that comprehensive services that consider the complex and interconnected needs of emerging adults experiencing homelessness may be more effective than interventions with a singular focus. There is little research that demonstrates how agencies that implement programs for individuals experiencing homelessness develop and sustain meaningful services for emerging adults, especially under conditions of increasing austerity. This study targets this gap in the literature by investigating how one transitional living program for emerging adults experiencing homelessness developed a music studio. Specifically, this study examines the factors and processes that were involved in developing, implementing, and sustaining the music studio. Findings suggest an ongoing organizational commitment to Positive Youth Development plays an important role.

Keywords: homelessness, Positive Youth Development, transitional living programs, programming, music-based services
\end{abstract}


Positive Youth Development: Developing and Sustaining Music-Based Services for Emerging Adults Experiencing Homelessness

There is a need for empirical knowledge regarding the effectiveness of homeless youth services (Milburn, Rosenthal \& Rotherram-Borus, 2005; Kidd, 2012). The majority of research focuses on factors that place young people at risk of experiencing homelessness, including an LGBTQ sexual identity (Rosario, Schrimshaw and Hunter, 2012a, 2012b) and family conflict (Congressional Research Service, 2013), and the consequences young people experience while homeless, including medical and behavioral health problems (Beharry, 2012; Edidin, Ganim, Hunter, \& Karnik, 2012; Kennedy, Tucker, Green Jr., Golinelli, \& Ewing, 2012; Stablein \& Appleton, 2013) and substance use and related effects (Ferguson, Jun, Bender, Thompson, \& Pollio, 2010). Meta-analysis findings suggest comprehensive interventions that consider the complex and interconnected needs of young people experiencing homelessness may be more effective than interventions with a singular focus (Slesnick, Dashora, Letcher, Erdem, \& Serovich, 2009).

Findings from descriptive studies of transitional living programs support this assertion, noting the important role of supportive services (Bartlett, Copeman, Golin, Miller, \& Needle, 2004; Giffords, Alonso, \& Bell, 2007), as well as the challenges in universally defining success for young people exiting transitional living programs (Nolan, 2006; Rashid, 2004). In a recent phenomenological study, former youth residents voice the importance of transitional living programs as spaces to experience connection and gain life skills (Holtschneider, 2016a). In a related study, former youth residents stress the importance of holistic services that help them realize self-defined goals and build community (Holtschneider, 2016b). Findings from a recent mixed-methods case study stress the importance of a non-judgmental, youth-centered approach 
in creating spaces for young people to develop and realize their goals (Leonard et al., 2017).

Positive Youth Development (PYD) offers an approach for developing such spaces.

PYD is a holistic, asset-based model for working with young people. It equally considers and incorporates their physical, intellectual, psychological, and emotional health, as well as their social development (U. S. Department of Health and Human Services, 2007). PYD promotes the positive development of youth and the factors that facilitate their wellbeing (Small \& Memmo, 2004). It promotes the inclusion of young people and their voices for the benefit of society at large; it considers the holistic development of youth for the benefit of all.

PYD is built on several important tenets (Damon, 2004; Dotterweich, 2006). These include the prioritization and celebration of the integral role that young people play in a healthy, vibrant society and the recognition, understanding, and practice that young people are the experts of their own experiences and lives. PYD promotes young people experimenting and making mistakes in safe environments, learning from their mistakes, and developing and mastering skills for their growth, and ultimately the growth of a healthy society. Several scholars note the Five C's of PYD, which represent important concepts and practices, a road map for what to include and look for in PYD program development, implementation, and evaluation (Damon, 2004;

Dotterweich, 2006). The Five C's are youth competence (e.g. motivation and ability), confidence (e.g. mastery and self-efficacy), character (e.g., individuality and insight), connection (e.g. sense of belonging), and contribution (e.g. involvement in one's life and world). Lerner (2005) adds a sixth $\mathrm{C}$ to list, and that is caring.

Youth workers have long used art and music-based services to engage young people, harness their talents, strengths, and interests, and assist them in healthy and holistic development (Kelly \& Doherty, 2017). This practice continues today and is well documented in the literature, 
including the role of community arts centers in fostering resilience among inner city youth (Rhodes \& Schechter, 2014), using the performing arts to engage young people's strengths (Delgado, 2017) and enhance positive youth development (Dutton, 2001), and using photography to engage young people in social and civic action (Bender, Begun, Dunn, Mackay, \& Dechants, 2018; Gant et al., 2009). Music-based services also show potential for engaging young people's strengths and assisting them in positive development (Baker \& Homan, 2007; Parker, Marturano, Lewis, \& Meek, 2018; Travis Jr., 2013; Travis Jr. \& Deepak, 2011, Wolf \& Wolf, 2012). Findings from recent ethnographic (Kelly, 2017) and audio documentary studies (Kelly, 2015; Kelly \& Hunter, 2016) demonstrate the efficacy of music-based services in a transitional living program as a means to engage the strengths of emerging adults experiencing homelessness. In addition, findings demonstrate that music-based services provide emerging adults with important opportunities for intra and interpersonal skill development and mastery, which is a key component of PYD.

These studies highlight the importance of transitional living programs, positive youth development, and music-based services, yet there is little research that explores how transitional living programs use positive youth development to build, implement, and sustain music-based services, especially under increasing conditions of austerity. As the availability of limited youth homelessness services are continually challenged, it is important for service providers and researchers to understand how agencies adapt and survive, and in doing so develop and provide meaningful services to the young people they serve. The current study addresses this gap in the literature, by investigating the following research question: What processes are involved in developing, implementing, and sustaining music-based services in a transitional living program for emerging adults experiencing homelessness? 


\section{Methodology}

\section{Site}

Teen Living Programs (TLP) provides services to young people experiencing homelessness on the south side of Chicago, IL, USA. Initially established to serve wards of the state and young people experiencing homelessness throughout Chicago, the agency shifted to solely serving homeless youth on the south side of Chicago in the 1990s to meet the growing needs of the area. This paradigmatic and programmatic shift in focus led to an interest and initial commitment to PYD, which resulted in increased intentionality around hiring staff with an understanding of PYD and the inclusion of residents' voice in program development. As the agency hired and trained staff on important PYD themes, including youth opportunity, competency, connection, supports, and contribution, it deepened its commitment to PYD and youth driven programming. Over time, this led to the development of supportive services, including educational, recreational, and vocational programming at Belfort House, the TLP transitional living program.

Belfort, as it is more colloquially known, provides transitional housing and supportive services for emerging adults experiencing homelessness between the ages of 18 to 21 for up to two years. As part of their comprehensive approach to supportive services, TLP offers recreational programming for residents, which includes access to an onsite music studio. All residents are eligible to use the studio. Supportive services staff with experience in music performance and production train those interested on how to use the studio equipment. While staff do not supervise residents in the studio, they are available to provide technical support as needed. 


\section{Sample}

While conducting observations in the music studio with residents and interviewing them about their experiences in the studio and the meaning they attach to their experiences for related ethnographic (Kelly, 2017) and audio documentary studies (Kelly, 2015; Kelly \& Hunter, 2016), I worked with the clinical director and the director of supportive services to identify candidates from staff for key informant interviews. The purpose of these interviews was to gather important contextual and historical information on the agency and to explore the processes that facilitated the development, implementation, and ongoing maintenance of the music studio. Given the focused nature of the interviews, nonprobability purposive and homogenous sampling provided useful frameworks for recruitment (Fortune and Reid, 1999). Nonprobability purposive sampling intentionally recruits individuals thought to exhibit the phenomenon under study, and homogenous sampling offers a focused form of recruitment that seeks to reduce variation in the sample, thereby simplifying analysis (Miles \& Huberman, 1994; Patton, 2001).

Seven staff members participated in the study $(N=7,2$ men, 5 women $)$. All staff initially identified and recruited for key informant interviews consented. Table 1 presents respondents' pseudonyms as well as their race, gender, age, and their time and role within the agency. At three different points in the findings I include data from interviews conducted with residents for the larger ethnographic study (Kelly, 2017). This data provides important context to the findings in the current study. I have listed these residents and their demographics in Table 1 as well. 
Table I

Respondents'Self-Reported Race, Gender, Age, Time with TLP, and Position (Staff Only)

\begin{tabular}{|c|c|c|c|c|c|}
\hline Respondent $^{\text {a }}$ & Race $^{\mathrm{b}}$ & Gender $^{\mathrm{c}}$ & Age $^{d}$ & Time with TLP ${ }^{\mathrm{e}}$ & Position (Staff Only) \\
\hline Staff: & & & & & \\
\hline Anne & $\mathrm{W}$ & $\mathrm{F}$ & 60 & $2 \mathrm{yr}$. & Executive Director \\
\hline Herman & W & M & 31 & $7 \mathrm{yr}$. & $\begin{array}{l}\text { Director of Supportive } \\
\text { Services }\end{array}$ \\
\hline Leigh & $\mathrm{W}$ & $\mathrm{F}$ & 33 & $4 \mathrm{yr}$. & Milieu Director \\
\hline Pepper & $\mathrm{AA}$ & $\mathrm{F}$ & 41 & $7.5 \mathrm{yr}$. & Clinical Director \\
\hline Ray & $\mathrm{AA}$ & M & 52 & $12.5 \mathrm{yr}$. & $\begin{array}{l}\text { Supportive Housing } \\
\text { Manage }\end{array}$ \\
\hline Rochelle & $\mathrm{W}$ & $\mathrm{F}$ & 51 & $10.5 \mathrm{yr}$ & Director of Operations \\
\hline Zee & $\mathrm{AA}$ & $\mathrm{F}$ & 24 & $1 \mathrm{yr}$. & $\begin{array}{l}\text { Youth Development } \\
\text { Specialist }\end{array}$ \\
\hline
\end{tabular}

Young people:

\begin{tabular}{lllll} 
Jay & AA & M & 21 & 6 mo. \\
Young Louie & AA & M & 22 & Former \\
\hline${ }^{\mathrm{a}}$ Pseudonyms used; ${ }^{\mathrm{b}}$ African American (AA) or White $(\mathrm{W}) ;{ }^{\mathrm{c}}$ female $(\mathrm{F})$ or male $(\mathrm{M}) ;{ }^{\mathrm{d}}$ in years; \\
${ }^{\mathrm{e}}$ in months (mo.) or years (yr.).
\end{tabular}

\section{Procedures}

Study interviews were conceptualized as research partnerships (Weiss, 1994), where the respondents and I explored the history of the agency and the development and sustainment of the studio. Following their identification, I approached candidates and invited them to participate in the interviews. Consent procedures and interviews occurred in private spaces within Belfort, often in a staff members' office. Interview questions focused on the history of TLP and Belfort, the agency's clinical philosophy and use of PYD, the development of the music studio, and the factors that contribute to its sustained existence. Interviews lasted between 53 and 105 minutes and were audio recorded with respondents' consent. As compensation for their time, interview 
participants received a $\$ 15$ iTunes gift certificate. The University of Illinois at Chicago Institutional Review Board approved all study procedures, protocol \#2011-0305.

\section{Analysis}

Interview recordings were transcribed, entered into NVivo (Version 8, 2008), and analyzed using Emerson, Fretz, and Shaw's (1995) model of coding and memoing. Emerson et al. (1995) outline an iterative, recursive two-phase model of data interpretation that supports a concurrent process of data collection and analysis. In the first phase of analysis, transcripts were closely read and treated as an entire data set. Transcripts were then openly coded and initial memos were made. During this phase codes were developed that represented respondents' roles with the agency, their understanding of the history of the agency, their understanding of the philosophy of the agency and its use of PYD, their understanding of the development of the music studio, the factors and processes that contribute to the sustained existence of the studio, and the role it plays within the agency.

In the second phase of data analysis, codes were coalesced and developed into themes, followed by more focused coding and integrative memoing. During this phase of analysis, initial codes were combined under the emerging themes organizational commitment to PYD and the music studio as a demonstration of organizational commitment to PYD. Transcripts were then coded with focused attention to these themes, resulting in the development of an initial thematic narrative that outlined the agency's organizational commitment to PYD and framed the music studio as a demonstration of the agency's organizational commitment to PYD. In order to ensure the authenticity and trustworthiness of the data (Lincoln \& Guba, 1985), initial findings were presented to staff during a member check group. No discrepancies arose. These findings were then used to develop the full thematic narrative presented in the Findings section. 


\section{Findings}

\section{Organizational Commitment to PYD}

Respondents describe an organizational commitment to PYD. In discussing their approach to PYD, respondents articulate a process that: (1) incorporates a strengths perspective in assessing and working with residents, (2) recognizes the importance of residents having a voice in defining and setting their goals, (3) creates opportunities for residents to define and set their own goals, (4) provides residents with opportunities to define success in ways that are meaningful to them, (5) challenges pre-conceived notions of what residents are capable of, a process whereby staff and residents work together to expand their definitions of success, and (6) provides residents with opportunities to take responsibility for their lives and accountability for their actions and decisions.

In describing how the agency approaches PYD, Leigh discusses the importance of incorporating a strengths perspective in assessing and working with residents.

Oftentimes as a society, we look at youth as volatile and negative and just trying to bear with it until they get to this adulthood where they can manage and contribute. For us, PYD is about the process and about the positivity that can happen throughout that process and the change that happens. And looking at the change is just something exciting. So building on a strength base, so looking at youth where their strengths are, where their growth is, how we can learn from them, how they can learn from us. So it's more of a community model than it is you're the client and we know everything and we're here to kind of be the experts, because they're the experts in their lives, and they help us understand where they're coming from and how we can help them.

Pepper builds on this idea and stresses the importance of meeting residents where they are.

You have to start with where your young person is and what their strengths are. It's a strength-based model. You could easily look at somebody and do a needs assessment and say what their deficits are. We want to start with, "Where are their strengths? What have they accomplished? What are they doing well?" Because when you can build from a strength, then people want to pursue success, as opposed to starting with what I can't do or what I don't have. 
Grounded in a strengths-based approach to working with residents, Herman describes

how staff create opportunities for residents to define and set their own goals.

We don't have a set of guidelines and "Here's how we define success and we're going to fit you in here and this is how it's going to work." We sit down and all the youth make their own goals through an Individual Action Plan. So, people come in and they set their own goals for what they want to do.

Pepper concurs and stresses the importance of bringing residents' voice into goal planning.

Sitting in a room and having everybody decide where you're going to go to school, what you're going to wear today, what's going to be for breakfast, ignores completely your input, your statement, what you have to say about it. But asking the question of, "Well, what do you think this should be like?" gives ear to the voice of the person.

Anne also talks about the importance of residents having a voice in defining and setting their goals. She notes how in doing so TLP provides residents with opportunities "to define success in ways that are meaningful to them."

Leigh expands on this notion of meeting residents where they are, and providing services and defining successes in ways that are meaningful for them. She also talks about pushing residents beyond their pre-conceived notions of what they are capable of. Through this collaborative process she describes how staff and residents work together to expand their definitions of success.

I think we try to create opportunities for youth to be successful instead of creating ways in which we look for their deficits. We're allowing youth to see that they are capable and they can be proud of themselves, and we're, hopefully, developing a framework and a base for them to start building a stronger sense of self and of self-esteem, because without those small successes, they're not gonna continue to move forward... a youth oftentimes looks at their parents, or whoever raised them, or friends, and they're like, "Well, I'm doing better than them." And so, they don't continue to grow because, "I'm doing better." So they've never been given the framework of, "You can do more. You don't have to settle"... I see part of PYD as giving them a different definition of success, and not what their parents or family or friends are saying is successful, but saying the world is an opportunity for you. 
Pepper adds that as staff and residents work together in establishing goals that have meaningful outcomes for residents that expand their definitions of success, they also remove excuses for failure.

I like to say we take away the excuses for failure. Failure's not an option. Whatever you need to be successful, based on your action plan, is here. If we don't have it, we'll partner, collaborate, link with somebody who does to make sure these young people get what they need to be successful. Success is defined by them.

Leigh contends PYD offers residents an opportunity to take responsibility for their lives

and accountability for their actions and decisions.

Accountability and consistency are two of the most important things. If you don't hold a youth accountable for what you say you're gonna hold them accountable for, it just shows them you're like everyone else, and they never know what to expect and so they're always gonna be pushing, pushing, pushing. So if a youth knows that "This is the expectation, I'm gonna hold you accountable, this has nothing to do with how I feel about you or how amazing I think you are. This is about holding the expectation for you," then I think it's starts to create that safety that we look to create for them, and to show them that if they know what to expect every time they walk in this building, regardless of what staff is here, it creates a safe place for them to be able to step outside of that and be creative or challenge something and know that we still care about them. They can challenge us, and it's still the same relationship. But if we don't have accountability... it creates an unsafe, unstable, unpredictable environment for them.

Staff members express several challenges in implementing PYD, including residents' preparedness to take accountability for their lives and responsibility for their actions and decisions, finding and hiring qualified staff, and allowing residents to make mistakes and manage the subsequent consequences. Pepper discusses the challenges she encounters personally and in working with staff around issues of control. She describes how some staff struggle with providing opportunities for residents to take control of their lives, fearing that they will make mistakes with serious consequences. Pepper notes how this is bound to happen and that it is the staff's job to assist residents in getting back up.

Sometimes you have to see that train wreck coming, and you have to let them wreck that train. Your role becomes being there in the midst of all of that, not kicking them while 
they're down, letting them work through the process, and then helping them learn from having been down there when they're ready. That's the hardest part about this model. Sometimes you got to see a train wreck and let it happen, cause you're not in control

\section{The Music Studio: A Demonstration of Organizational Commitment to PYD}

Respondents provide a detailed account of the development of the music studio and the factors that contribute to its ongoing maintenance. In doing so, they frame the studio as a demonstration and embodiment of the agency's PYD informed, strengths-based approach to recreational programming.

Developing recreational programming and the music studio. Herman describes how residents responded positively to initial recreational programming and how it served as a means of engagement to other supportive services.

What we noticed was that when we came in and offered field trips, music lessons, martial arts, and all these different kinds of things, the youth really responded to it. We found that people were staying in the program longer. Reasons that people were saying, maybe after they left, when they came back, that they wanted to continue on with the recreation programming, that the services we were offering - Recreation was what was really keeping people around. That was, in fact, helping fuel them to do their education, then get a job, things like that.

Herman talks about initially developing programs and activities (e.g., creative writing groups)

grounded in his interest and orientation and his realization of the limitations of this approach.

We'd have writing groups, people weren't bringing in writing, they were bringing in raps. People would come in and freestyle or do whatever. I can remember having the thought in my head... "How can I explain to everybody here that, you know, freestyling is not as good as this serious writing, because of A, B, and C." Then, I started looking at myself, and I started thinking, "Well, maybe I have it wrong. Maybe I'm the one who has this mixed up." And I did.

Herman began to incorporate residents' interests in recreation programming, which led to the development of open microphone nights. In addition, Herman and other musically trained staff began offering guitar and piano lessons. Herman talks about coming to an additional awareness around what kinds of music-based activities residents were seeking and his and the 
agency's willingness to provide access to those activities, thereby bringing residents' voice further into recreational program development.

My interests and knowledge of music was completely different from what the youth were interested in. They're much more hip hop focused - the folks I was working with at least - and I never listened to a lot of hip hop growing up. So, I could sit down and give a classical musical lecture, but I can't sit down and give a hip hop lecture 'cause I don't know enough about it to be able to teach anybody. What we did was I talked to this guy and I was like, "What would be beneficial for you? These guitar lessons I don't think are doing the trick for you." He was saying, "Well, if I had beats, I could do that. If I could record music..." I thought, "Okay, I have a portable digital recorder at my house I've used for years and I'm not using it right now." So, I started bringing it back and forth on the train and I would drop it off for him for a weekend or for a day.

Herman goes on to discuss how he framed access to his equipment as a leveraging tool to get the young man engaged in school and notes the larger positive impact he believes the experience had on him (e.g., GED completion). Armed with this anecdotal data, Herman approached Pepper about purchasing recording equipment for Belfort. Pepper recalls approving the purchase of the recording equipment, framing the decision as an extension of the agency's approach to working with young people.

Herman pitched this idea and I really liked it. I think it was another way to reach young people where they were, as opposed to, you know - Some people don't want to sit across from you and talk to you. Some people want to zone out and write music, or listen to beats or create rhythms. That's how they do it... It wasn't hard to sell me on it, 'cause I got it. I felt it was another way in which we could creatively allow young people to go in and harness their own creativity and have something to show for it, that they created.

With Pepper's approval and support from the agency, Herman bought some instruments, recording equipment, and began the process of developing a music studio in 2007. ${ }^{1}$ After several months of residents checking the recording equipment out of a closet and working on music in their rooms, an offer from a volunteer group provided an opportunity to build out a permanent studio space in the basement of Belfort. Herman approached the administrative team with the

\footnotetext{
${ }^{1}$ Herman purchased an electric guitar, 2 acoustic guitars, a Korg D1200 Digital Recorder, and a Shure SM58LC Microphone. In addition, 2 upright pianos were donated from a music school.
} 
proposal and they approved the build out. By providing physical space for the studio they demonstrated an organizational willingness to support recreational programming grounded in young people's interests.

The music studio developed an identity as residents engaged with it (i.e., producing tracks, listening to music, and hanging out in the space). Herman trained residents on how to use the recording equipment, thereby helping them access the studio and increase studio utilization. In addition, he describes how the studio engaged disconnected residents and how staff used the studio as a leveraging tool in an effort to encourage young people to work on their education goals.

The big thing that we noticed was that a lot of the folks who were having difficulties in the program - whether it was going to school or getting a job or just kind of abiding by the rules generally - we noticed they were really using the studio. People that were really disconnected with the program - that's where their interest was. Just like with the first guy we worked with, it was kind like, "Well, if you guys want to use the studio, then we're going to have an equal number of hours of you studying for your GED or high school diplomas or what have you." They would just do it right away.

Herman goes on to describe the studio as a youth centered space, where residents engaged their strengths and talents and formed collaborations.

People were starting to hang out with their friends at that point down there. It'd become a cool social setting actually. People were really kind of invested in the music people were recording. You know, if somebody had a couple songs and somebody could sing a little bit, maybe they sing a hook... People were all invested. People were using their talents in the music studio.

Studio thefts and incorporating accountability. In late 2007, as momentum built around the studio and residents increasingly defined it as their space, the equipment was stolen. Rochelle recalls the incident.

Young people that were either living in the house or had shortly before left the house, took the equipment, and, you know, ran off with it. So, we were without a music studio for a while. That was really a blow... a broken trust kind of thing. I mean nobody expects 
young people to resist every temptation that is put in front of them, but that felt like - I know the young people felt really betrayed by their peers that had done this.

Herman recalls the overall impact of the theft on the residents as well.

People were really devastated. What was really difficult for some of the guys that were working in there - they had logged, some guys, hundreds of hours and recorded one or two full CDs. All their stuff was gone. They had lost all their stuff. These guys who were the most hardcore guys that we had here - these guys were almost in tears because they couldn't believe that they'd spent all this time and someone had stolen all their equipment.

In summarizing the impact of the theft, Herman states, "This sounds really extreme, but it was like somebody died." This comparison speaks to the revered position the studio acquired within the agency: a respected place of importance and meaningfulness.

Rather than abandon the studio, the agency slowly rebuilt it by employing various fundraising techniques, including resident led car washes and bake sales. In addition, the development department received an invitation for residents to write and record a song for an HIV awareness campaign, which served as an additional catalyst to rebuild the studio. Rochelle recalls her hesitancy in rebuilding the studio from an administrative perspective. "As an administrator in the agency, I was not anxious to put more equipment into the same space until we had developed appropriate safeguards to prevent something like this from happening again." In responding to the agency's concerns around developing appropriate safeguards, Herman notes, "I did a lot of research on how to secure the equipment," adding, "Once we had the new equipment, we had it locked down. We had it locked down significantly well."

With funds raised and approval from the agency, TLP began the process of rebuilding the studio. Herman describes how residents' interests were given primary consideration in purchasing the new equipment.

(The) first (studio) equipment we purchased was purchased off of my knowledge of digital recording, which is going to be consistent with my interest in music, which, at the 
time, most of my expertise was in recording instruments, not in doing hip hop, not in doing these kinds of things. What I wanted to do was make sure that the equipment was geared towards what they wanted to do. ${ }^{2}$

Herman links this shift in perspective to PYD.

If we weren't using PYD, we would probably have a couple electric guitars in our studio... We might be instructing them for intense music theory on a chalkboard and that's happened here before, in the past. We're away from that now, because we know it doesn't work, and people are interested in different ways of learning the material or music in general.

With new equipment purchased, residents began to work in the studio again. Herman

describes how studio utilization increased, noting a previously unseen level of interest and engagement, particularly on Friday and Saturday nights.

For some people who are using the studio, not everybody, but for some folks, going to the park and getting high was a normal thing to do on a Friday, Saturday night. Folks would occasionally run into issue with that, with police or other people in the park or all these other factors that can happen when people are outside, late at night. It wasn't our intent to cut that off or anything like that, but it just kind of naturally happened that "I'd rather - my time is better spent making music. It's more fun than doing this other stuff I used to do." That was - That's really powerful, to have a computer system completely enrapture these youth's minds. "I'm not going to go out on a Friday or Saturday night. I'm 19, I'm going to stay home, late at night, and work on music in the studio."

Herman goes on to talk about this realization as key in his developing understanding of what the studio was providing residents and the vital role it plays within the agency. "That was a tipping point, in my mind at least, to be like, "This is really important. We have to hold onto this."

In 2009, the agency moved into a new building. The supportive services department, including the music studio, remained in the old building while the agency settled into its new space. That spring the old building was broken into and the studio equipment was stolen again.

Leigh, an intern at the time, recalls the incident.

There was a huge loss I think for what was stolen from the youth, and kind of that a lot of the youth at the time wanted to be music producers and in the industry, and whether that

\footnotetext{
${ }^{2}$ For the second iteration of the studio Herman purchased an Apple IMac Desktop, Logic Pro 8 software, an MAudio Midi Device, 2 Shure SM58LC microphones, a stereo amplifier, and 2 speakers.
} 
was a realistic expectation, it was a dream, and it was hope, and you don't see that a lot. They took that away and it was really sad and there was a lot of I think tears and anger and frustration and it was a really sad time, a really scary time.

Ray concurs by adding, "A lot of people were let down, staff and residents, because the hope was so high for the studio. And to have somebody just come and take the equipment and run off with it hurt a lot of people." Young Louie who was a resident at the time reflects on how he felt. "Very, very terrible and sad. Just all my work that I worked hard for was just erased."

After the second theft, the agency grappled with how to proceed with the studio. Clearly there were benefits to the studio. It provided residents with opportunities for creative expression and increased engagement in other supportive services. Yet, there was hesitancy among staff to rebuild the studio, particularly in light of previous assurances that it was secure. Regardless, Herman approached the agency about developing a studio in the new building. Pepper recalls supporting Herman in making the pitch to the rest of the executive team.

I believe in it so strongly and seen it work over the years that I would pitch it to anybody who would listen and had the money. If you got the money, it's not a lot [laughs]. You know. You think about what the benefits are. The costs are way under the benefits for the studio. That also made it an easy sell.

Rochelle concurs with Pepper, noting the importance of the studio while at the same time making a demand for a stronger security plan.

From a clinical standpoint, from a services standpoint, it's a valuable thing, and I didn't object to it at any level from that perspective. My perspective was always just make sure this doesn't get stolen again.

The executive team approved the purchase of new studio equipment with a mandate to develop increased security measures. Herman worked with staff and residents to develop processes to safeguard the studio, including a studio orientation. Jay, a resident, recalls his experience of the orientation. "They taught all of its functions, how to hook up the microphone, how to create sounds and beats off of it, how to use the mini keyboard, how to use Logic 
(production software)." Following the orientation, Herman provides residents with a test that assesses their basic understanding of the studio equipment and troubleshooting procedures. While some struggle with the test, Herman contends that it prepares them to engage with and utilize the studio in an effective and productive manner. Residents are also required to "checkout" equipment (i.e., cables, headphones, etc.) in order to use the studio. If they leave the studio for any reason they are required to go through a similar process of finding a staff member to check the equipment back in. Herman notes this process "keeps people accountable" and "keeps the equipment safe."

In discussing accountability and security around the studio, Rochelle states, "I don't think that the young people are responsible for making sure that that's safe. I think staff are responsible for making sure that that's safe." Pepper picks up on this idea of staff accountability as well.

We have a full inventory that all of our staff are trained on and a manual - they know there's an inventory log there - all these things should be present when you're checking in and checking out and young people's signatures there just like our signature is there. If we lose something on our watch, I mean you could be accountable for replacing it. That's huge, when the agency says, "Okay, we're invested. We purchased it. We're accountable. We've secured it. We've put the structure around it. And we're making you financially accountable to it as a staff member"... It's an essential part of programming. We've invested money and time. We should be accountable.

It is clear that Herman plays an important role around the studio. From developing strengths-based recreational programming, to loaning residents his recording equipment, to advocating for multiple equipment repurchases after the thefts, to incorporating young people's interests, strengths, and talents in each iteration of the studio, he has demonstrably played a vital role in the development of the studio and its ongoing existence. Yet, Herman pushes back on the notion that he played a significant role in the development of the studio, citing that it was inevitable based on young people's interest. Rochelle agrees, noting that while staff certainly 
played a role in reopening the studio, residents' voice played the most important role. She

articulates reopening the studio as a demonstration of the agency's commitment to PYD.

Well, certainly youth want this. And I can't imagine us just saying, "Well, then we don't care about it anymore." I think that youth voice was really important in the decision to reopen it. Youth were clamoring for it. Certainly, staff were articulating it, but it was - it wasn't staff that really want to do this. It was the youth really want it. So, I think it's a demonstration of our commitment to PYD that we were willing to kind of go through these steps we might not normally have gone through because of the sort of high demand factor.

In 2011, the studio reopened in the new building. ${ }^{3}$ Zee notes how it remains an important

space for residents, particularly for those who are less active in the milieu.

Some of the youth who are in the studio a lot are the ones who keep to themselves when they're in the milieu. But I've noticed that these particular youth who are in the studio, they really open up, and it's just great seeing them in that light, and I feel like some people may miss that side of that youth because they don't see how they are in the studio versus how they interact with others here in the milieu. I think it's awesome, just seeing them in a different light and learning about their interest as well as just having the opportunity just to kind of just feed off that positive energy that they have while they're in the studio.

\section{Discussion}

Respondents describe an organizational commitment to PYD that incorporates a strengths perspective and recognizes residents' voices in defining and setting their goals. In doing so residents are able to define success in ways that are meaningful to them, move beyond their preconceived notions of success, and take reasonability for their lives and accountability for their actions. Respondents frame the development of the music studio as a demonstration and embodiment of the agency's organizational commitment to PYD, specifically by applying a PYD informed, strengths-based approach to recreational programming.

\footnotetext{
${ }^{3}$ For the third iteration of the studio Herman purchased a refurbished Apple IMac Desktop, Logic Pro 9 software, a Korg X5 synthesizer, 2 Shure SM58LC microphones, an M-Audio USB Audio/MIDI Interface with Preamps, and 2 sets of headphones.
} 
By focusing on developing and supporting art and music-based recreational services that were responsive to young people's interests, including writing groups focused on rap and spoken word work, guitar and piano lessons, talent shows, loaning personal recording equipment to residents, and the eventual development of the music studio, TLP created opportunities for residents to explore their interests and find their creative voice. Residents' voices and interests have continually shaped the development of the studio (e.g., the purchasing of electronic and beat oriented hardware and software, as opposed to instruments for the second and third iterations of the studio) and its ongoing maintenance (e.g., participating in accountability and security measures). By providing residents with opportunities to participate in the ongoing development and sustainment of the studio, TLP provides them with opportunities to expand their definition of success and to do so in ways that are meaningful to them.

This approach to working with young people reflects several key elements of PYD, including creating opportunities for young people to "move from being taken care of to taking care of themselves," as well as providing practitioners with "a set of practices," to use in providing young people, "with the types of relationships and experiences needed to fuel healthy development" (Ansell et al., 2008, p. 6). In discussing their approach to PYD and the development and sustainment of the studio, respondents describe a process whereby the agency is building on what Ansell at al. (2008) describe as the importance of developing "safe and structured spaces" for young people and emerging adults to "recreate and socialize," as well as “increased opportunities and avenues for positive use of time," and "self-expression" (p. 7)

In discussing their approach to PYD, respondents did not explicitly reference the Six C's described in the literature (Lerner, 2005). Findings from related ethnographic (Kelly, 2017) and audio documentary studies (Kelly, 2015; Kelly \& Hunter, 2016) with the residents who engage 
in the music studio demonstrate that they display competence (e.g., studio related skill development), confidence (e.g., overcoming studio related technical challenges), connection (e.g., working through studio related relational challenges), character (e.g., utilizing music production in the studio as a form of expression), caring (e.g., taking time to share with and teach each other), and contribution (e.g., giving back to the studio through peer mentoring and teaching) as it relates to music production, music education, and music appreciation in the studio.

These findings suggest the TLP has successfully implemented PYD in their approach to working with emerging adults experiencing homelessness and that the music studio is an important demonstration of their commitment to this approach. In doing so they have created a young-person centered space for creative expression, belonging, and mastery, all of which are important components of PYD (Ansell et al., 2008). Given the lack of empirical knowledge regarding the effectiveness of homeless youth services and interventions (Milburn, Rosenthal, \& Rotherram-Borus, 2005; Kidd, 2012), including transitional living programs and the use of music-based activities in working with emerging adults experiencing homelessness, it is important to consider the impact of TLP's decision to adapt, develop, and successfully implement a strengths-based, PYD approach to working with emerging adults experiencing homelessness and the outcomes of doing so. By listening to residents and incorporating their interests and voices in recreational services development and implementation, the agency established and sustained the TLP music studio.

\section{Implications}

This study provides important insight into ways in which service providers and organizations working with emerging adults experiencing homelessness may incorporate a PYD approach in program development, implementation, and sustainment. In this study, the 
successful adaptation and implementation of PYD facilitated the development of the music studio and sustained its existence; it was pivotal in the development of a space for emerging adults, and ultimately designed by emerging adults. This suggests that agencies seeking to successfully provide emerging adults experiencing homelessness with recreational, art, and/or music-based activities may best do so through a PYD approach.

Incorporating a PYD approach in homelessness services offers opportunities to harness and build on emerging adults talents, strengths, and interests. In doing so, service providers may support research that challenges the dominant risks and consequences narrative in youth homelessness literature (Alvi, Scott, \& Stanyon, 2010; Beharry, 2012; Walls \& Bell, 2011; Coates \& McKenzie-Mohr, 2010; Edidin, Ganim, Hunter, \& Karnik, 2012; Ferguson, Jun, Bender, Thompson, \& Pollio, 2010; Ferguson \& Xie, 2012; Kennedy, Tucker, Green Jr., Golinelli, \& Ewing, 2012; Ober, Martino, Ewing, \& Tucker, 2012; Rosario, Schrimshaw, \& Hunter 2012a, Rosario, Schrimshaw, \& Hunter, 2012b; Tucker et al., 2012), and support the idea that emerging adults experiencing homelessness have strengths and are eager to engage in meaningful services (Karabanow, Hughes, Ticknor, Kidd, \& Patterson, 2010; Kidd \& Evans, 2011).

One need only observe the imbalance in the above citations to gain a sense of the power and pull of the risks and consequences narrative in youth homelessness research. The ongoing focus on the individual risk-oriented attributes of young people experiencing homelessness, which are most often framed from a deficits perspective, is failing to offer useful solutions (Kidd, 2012). In developing, implementing, and sustaining a PYD approach to recreational services for young people experiencing homelessness, TLP offers one solution for engaging emerging adults experiencing homelessness in music-based services that are meaningful to them. 


\section{Limitations}

Findings from this study should be interpreted as contextually specific. The exploration of only one agency and recruitment of a small sample size limits the generalizability of the findings presented in this study. That being said, the selection of one case allowed for an indepth examination of the processes involved in promoting and developing the TLP music studio. Additional research is needed to determine if the application of PYD at other transitional living programs for emerging adults experiencing homelessness would result in the development, implementation, and sustainment of meaningful recreational services, including music-based services, for residents. In addition, the use of nonprobability purposive and homogenous sampling limited variation within the findings. I did not interview staff without historical and/or practical knowledge of the studio, which may have provided different perspectives on how the studio developed and its role within the agency. Additional research is needed to determine if other staff in other transitional living programs for emerging adults experiencing homelessness experience PYD informed recreational services similarly.

\section{Conclusion}

Transitional living programs provide important services to emerging adults experiencing homelessness. By incorporating a PYD in program development and implementation, TLP Belfort developed meaningful recreational services for the residents they serve, including a music studio. The agency's ongoing organizational commitment to PYD resulted in rebuilding the studio twice and incorporating residents' interests and voice in the process. Ultimately, the studio serves as an embodiment and demonstration of the agency's commitment to PYD. 


\section{References}

Alvi, S., Scott, H., \& Stanyon, W. (2010). "We're locking the door": Family histories in a sample of homeless youth. The Qualitative Report, 15(5), 1209-1226. Retrieved from http://nsuworks.nova.edu/tqr/vol15/iss5/10

Ansell, D. J., Burns, P., Carpenter-Williams, J., Cassidy, T., Finck, C., Peck Jr., R. W., ... ...Zanghi, M. (2008). 2008 positive youth development toolkit: Engaging youth in program development, design, implementation, and service delivery. Tulsa, OK.

Baker, S., \& Homan, S. (2007). Rap, recidivism and the creative self: A popular music programme for young offenders in detention. Journal of Youth Studies, 10(4), 459-476. doi: $10.1080 / 13676260701262566$

Bartlett, M., Copeman, A., Golin, J., Miller, D., \& Needle, E. (2004). Unlocking the potential of homeless older adolescents: Factors influencing client success in four New England transitional living programs. New England: Network for Child, Youth, \& Family Services.

Beharry, M. S. (2012). Health issues in the homeless youth population. Pediatrics Annals, 41(4), 154-156. doi: 10.3928/00904481-20120307-12

Bender, K., Begun, S., Dunn, K., Mackay, E., \& Dechants, J. (2018). Homeless Youths’ Interests in Social Action via Photovoice. Journal of Community Practice, 26(1), 107-120. doi: $10.1080 / 10705422.2017 .1413027$

Coates, J., \& McKenzie-Mohr, S. (2010). Out of the frying pan, into the fire: Trauma in the lives of homeless youth prior to and during homelessness. Journal of Sociology and Social Welfare, 37(4), 65-96. doi: 10.1080/00224499.2010.501916. 
Damon, W. (2004). What is positive youth development? The ANNALS of the American Academy of Political and Social Science, 591(1), 13-24. http://doi.org/10.1177/0002716203260092

Delgado, M. (2017). Music, song, dance, theater: Broadway meets social justice youth community practice. Oxford University Press.

Dutton, S. E. (2001). Urban youth development-Broadway style: Using theatre and group work as vehicles for positive youth development. Social Work with Groups, 23(4), 39-58. doi: 10.1300/J009v23n04_04

Dotterweich, J. (2006). Positive Youth Development Resource Manual. Retrieved from http://ecommons.cornell.edu/handle/1813/21946

Edidin, J. P., Ganim, Z., Hunter, S. J., \& Karnik, N. S. (2012). The mental and physical health of homeless youth: A literature review. Child Psychiatry \& Human Development, 43(3), 354-375. doi: 10.1007/s10578-011-0270-1

Emerson, R., Fretz, R., \& Shaw, L. (1995). Writing ethnographic fieldnotes. Chicago, IL: The University of Chicago Press.

Ferguson, K. M., Jun, J., Bender, K., Thompson, S., \& Pollio, D. (2010). A comparison of addiction and transience among street youth: Los Angeles, California, Austin, Texas, and St. Louis, Missouri. Community Mental Health Journal, 46(3), 296-307. doi: 10.1007/s10597-009-9264-X

Ferguson, K. M., \& Xie, B. (2012). Adult support and substance use among homeless youth who attend high school. Child \& Youth Care Forum, 41(5), 427-445. doi: 10.1007/s10566012-9175-9 
Fortune, A. E., \& Reid, W. J. (1999). Research in social work (3rd ed.). New York, NY: Columbia University Press.

Gant, L. M., Shimshock, K., Allen-Meares, P., Smith, L., Miller, P., Hollingsworth, L. A. \& Shanks, T. (2009). Effects of photovoice: Civic engagement among older youth in urban communities. Journal of Community Practice, 17(4), 358-376. doi: $10.1080 / 10705420903300074$

Giffords, E. D., Alonso, C., \& Bell, R. (2007). A transitional living program for homeless adolescents: A case study. Child Youth Care Forum, 36(4), 141-151. doi: 10.1007/s10566-007-9036-0

Holtschneider, C. (2016a). A part of something: The importance of transitional living programs within a housing first framework for youth experiencing homelessness. Children and Youth Services Review, 65, 204-215. doi: 10.1016/j.childyouth.2016.04.009

Holtschneider, C. (2016b). From independence to interdependence: Redefining outcomes for Transitional Living Programs for youth experiencing homelessness. Families in Society 97(3): 160-170.

Karabanow, J., Hughes, J., Ticknor, J., Kidd, S., \& Patterson, D. (2010). The economics of being young and poor: How homeless youth survive in neo-liberal times. Journal of Sociology \& Social Welfare, 37(4), 39-63.

Kelly, B. L. (2015). Using audio documentary to engage young people experiencing homelessness in strengths-based group work. Social Work with Groups, 38(1), 68-86. doi: $10.1080 / 01609513.2014 .931665$ 
Kelly, B. L. (2017). Music-based services for young people experiencing homelessness: Engaging strengths and creating opportunities. Families in Society, 98(1), 57-68. doi: $10.1606 / 1044-3894.2017 .9$

Kelly, B. L., \& Doherty, L. (2017). A historical overview of art and music-based activities in social work with groups: Nondeliberative practice and engaging young people's strengths. Social Work with Groups, 40(3). doi: 10.1080/01609513.2015.1091700

Kelly, B. L., \& Hunter M. J. (2016). Exploring group dynamics in activity-based group work with young people experiencing homelessness. Social Work with Groups, 39(4), 307-325. doi: $10.1080 / 01609513.2015 .1061962$

Kennedy, D. P., Tucker, J. S., Green Jr., H. D., Golinelli, D., \& Ewing, B. (2012). Unprotected sex of homeless youth: Results from a multilevel dyadic analysis of individual, social network, and relationship factors. AIDS and Behavior, 16(7), 2015-2032. doi: $10.1007 / \mathrm{s} 10461-012-0195-0$

Kidd, S. (2012). Invited commentary: Seeking a coherent strategy in our response to homeless and street-involved youth: A historical review and suggested future directions. Journal of Youth and Adolescence, 41(5), 533-543. doi: 10.1007/s10964-012-9743-1

Kidd, S., \& Evans, J. D. (2011). Home is where you draw strength and rest: The meanings of home for houseless young people. Youth \& Society, 43(2), 752-773. doi:

\section{$10.1177 / 0044118 X 10374018$}

Leonard, N. R., Freeman, R., Ritchie, A. S., Gwadz, M. V., Tabac, L., Dickson, V. V., ... \& Hirsh, M. (2017). "Coming from the place of walking with the youth - that feeds everything": A mixed methods case study of a runaway and homeless youth 
organization. Child and Adolescent Social Work Journal, 34(5), 443-459. doi:

$10.1007 / \mathrm{s} 10560-016-0483-\mathrm{Z}$

Lerner, R. M. (2005). Promoting positive youth development: Theoretical and empirical bases. National Research Council/Institute of Medicine. Washington, DC: National Academies of Science.

Lincoln, Y. S., \& Guba, E. G. (1985). Naturalistic inquiry. Beverly Hills, CA: Sage Publications.

Milburn, N. G., Rosenthal, D., \& Rotheram-Borus, M. J. (2005). Needed: Services research with homeless young people. Journal of Health \& Social Policy, 20(3), 1-9. http://dx.doi.org/10.1300/J045v20n03_01

Miles, M. B., \& Huberman, A. M. (1994). Qualitative data analysis (2nd ed.). Thousand Oaks, CA: Sage Publications.

Nolan, T. (2006). Outcomes for a transitional living program serving LGBTQ youth in New York City. Child Welfare, 85(2), 385-406.

NVivo. (2008). (Version 8) [Computer Software]. Burlington, MA: QSR International Pty. Ltd.

Ober, A. J., Martino, S. C., Ewing, B., \& Tucker, J. S. (2012). If you provide the test, they will take it: Factors associated with HIV/STI testing in a representative sample of homeless youth in Los Angeles. AIDS Education and Prevention, 24(4), 350-362. doi:

10.1521/aeap.2012.24.4.350

Parker, A., Marturano, N., Lewis, G., \& Meek, R. (2018). Marginalised youth, criminal justice and performing arts: Young people's experiences of music-making. Journal of Youth Studies. doi: 10.1080/13676261.2018.1445205 
Patton, M. Q. (2001). Qualitative evaluation and research methods (3rd ed.). Thousand Oaks, CA: Sage Publications.

Rashid, S. (2004). Evaluating a transitional living program for homeless, former foster care youth. Research on Social Work Practice, 14(4), 240-248. doi: $10.1177 / 1049731503257883$

Rhodes, A. M., \& Schechter, R. (2014). Fostering resilience among youth in inner city community arts centers: The case of the artists collective. Education and Urban Society, 46(7), 826-848. doi: 10.1177/0013124512469816

Rosario, M., Schrimshaw, E. W., \& Hunter, J. (2012a). Homelessness among lesbian, gay, and bisexual youth: Implications for subsequent internalizing and externalizing symptoms. Journal of Youth and Adolescence, 41(5), 544-560. doi: 10.1007/s10964-011-9681-3

Rosario, M., Schrimshaw, E. W., \& Hunter, J. (2012b). Risk factors for homelessness among lesbian, gay, and bisexual youths: A developmental milestone approach. Child and Youth Services Review, 34(1), 186-193. doi: 10.1016/j.childyouth.2011.09.016

Slesnick, N., Dashora, P., Letcher, A., Erdem, G., \& Serovich, J. (2009). A review of services and interventions for runaway and homeless youth: Moving forward. Children and Youth Services Review, 31(7), 732-742. http://dx.doi.org/10.1016/j.childyouth.2009.01.006

Small, S., \& Memmo, M. (2004). Contemporary models of youth development and problem prevention: Toward an integration of terms, concepts, and models. Family Relations, 53(1), 3-11. doi: 10.1111/j.1741-3729.2004.00002.x

Stablein, T., \& Appleton, A. A. (2013). A longitudinal examination of adolescent and young adult homeless experience, life course transitions, and health. Emerging Adulthood, 1(4), 305-313. 
Strauss, A., \& Corbin, J. (1998). Basics of qualitative research: Techniques and procedures for developing grounded theory (2nd ed.). Thousand Oaks, CA: Sage Publications.

Travis Jr., R. (2013). Rap music and the empowerment of today's youth: Evidence in everyday music listening, music therapy, and commercial rap music. Child and Adolescent Social Work Journal, 30(2), 139-167. doi: 10.1007/s10560-012-0285-x

Travis Jr., R., \& Deepak, A. (2011). Empowerment in context: Lessons from hip-hop culture for social work practice. Journal of Ethnic \& Cultural Diversity in Social Work, 20(3), 203222.

Tucker, J., Ryan, G., Golinelli, D., Ewing, B., Wenzel, S., Kennedy, D., ... Zhou, A. (2012). Substance use and other risk factors for unprotected sex: Results from an event-based study of homeless youth. AIDS \& Behavior, 16(6), 1699-1707. https://doi.org/10.1007/s10461-011-0017-9

U. S. Department of Health and Human Services. (2007). Promising strategies to end youth homelessness. Rockville, MD.

Walls, N. E., \& Bell, S. (2011). Correlates of engaging in survival sex among homeless youth and young adults. Journal of Sex Research, 48(5), 423-436. http://dx.doi.org/10.1080/00224499.2010.501916

Weiss, R. (1994). Learning from strangers: The art and method of qualitative interview studies. New York, NY: The Free Press.

Wolf, L., \& Wolf, D. (2012). May the songs I have written speak for me: An exploration of the potential of music in juvenile justice. San Franciso, CA: Wolf Brown. Retrieved from http://wolfbrown.com/images/articles/May_the_Songs_I_Have_Written_Speak_for_Me.p df 